CARDIOVASCULAR MEDICINE

\title{
Effects of angiotensin converting enzyme inhibitors in hypertensive patients with aortic valve stenosis: a drug withdrawal study
}

\author{
J Jiménez-Candil, J Bermejo, R Yotti, C Cortina, M Moreno, J L Cantalapiedra, \\ M A García-Fernández
}

Heart 2005;91:1311-1318. doi: 10.1136/hrt.2004.047233

See end of article for
authors' affiliations
$\ldots \ldots \ldots \ldots \ldots \ldots \ldots \ldots . \ldots . \ldots . .$.
Correspondence to:
Dr Javier Bermejo,
Laboratory of
Echocardiography,
Department of Cardiology,
Hospital General
Universitario Gregorio
Marañón, Dr Esquerdo 46,
28007 Madrid, Spain;
javbermejo@jet.es
Accepted
14 December 2004

\begin{abstract}
Objective: To determine the effects of angiotensin converting enzyme (ACE) inhibitors in hypertensive patients with aortic valve stenosis (AS).

Design: Observational, drug withdrawal, single blinded study, with randomisation of the order of tests. Setting: Hypertension and asymptomatic AS.

Patients and interventions: 20 patients (aged 73 (9) years, valve area $0.7(0.3) \mathrm{cm}^{2}$, left ventricular ejection fraction $\geqslant 45 \%$ ) were enrolled. Each patient underwent two sets of tests (with and without taking the drug), each of which included clinical evaluation, Doppler echocardiogram, and symptom limited exercise echocardiography.

Main outcome measures: Functional and haemodynamic variables while taking and not taking ACE inhibitors.

Results: Drug intervention induced no change in patients' subjective functional class. While taking ACE inhibitors, patients had a lower systolic blood pressure $(140$ (18) mm Hg with ACE inhibitors $v 159$ (12) $\mathrm{mm} \mathrm{Hg}$ without ACE inhibitors, $p=0.02$ ), a higher mean pressure gradient (34 (15) mm Hg $v 28$ (18) $\mathrm{mm} \mathrm{Hg}, \mathrm{p}=0.037$ ), and a higher left ventricular stroke work loss (19 (6)\% v 14 (10)\%, $\mathrm{p}=0.009)$. Other baseline functional and haemodynamic parameters were unmodified. Five patients had an abnormal blood pressure response during one of the exercise tests (two patients while taking the drug and three patients while not taking the drug). When taking ACE inhibitors, patients had a higher stroke volume at peak stress $(59$ (11) $\mathrm{ml} \vee 54(25) \mathrm{ml}, \mathrm{p}=0.046)$. All other stress variables remained constant.

Conclusions: In AS, the afterload relief caused by ACE inhibitors is blunted by a parallel increase in the pressure gradient. However, ACE inhibitors favourably affect stress haemodynamic function in most hypertensive patients with AS and should not be discontinued.
\end{abstract}

\section{A} ortic valve stenosis (AS) affects $2-7 \%$ of the elderly population. ${ }^{1}$ Almost one third of patients with AS have concomitant systemic hypertension. ${ }^{2}$ Because patients with AS are known to be at a high risk for adverse cardiovascular events, ${ }^{3}$ control of blood pressure should be of major relevance in this population.

Lowering blood pressure is particularly difficult in patients with AS because of the complex adaptation of the cardiovascular system to left ventricular (LV) outflow obstruction. Drugs that are safely used to treat isolated hypertension may cause adverse cardiovascular effects in patients with a fixed cardiac output. Diuretics, $\beta$ and $\alpha$ blocking agents, calcium antagonists, and inhibitors of the renin-angiotensin-aldosterone system need to be used with caution by patients with AS, since they are particularly sensitive to manipulations of preload, contractility, and vasomotor tone. ${ }^{4}$

Angiotensin converting enzyme (ACE) inhibitors are well established drugs for treating hypertension. ACE inhibitors have also been shown to reduce mortality and morbidity in some patient groups, such as those with impaired systolic function, ${ }^{5}$ with diabetic nephropathy, ${ }^{6}$ or at high risk for cardiovascular events. ${ }^{7}$ Importantly, these favourable effects of ACE inhibitors are independent of their effect on blood pressure. Experimental evidence suggests additional potential benefits of ACE inhibitors on AS. The identification of ACE and angiotensin activity in the tissue of degenerative aortic valves indirectly suggests a potential role of ACE inhibitors in slowing disease progression. ${ }^{8}$ Also, ACE activity is known to modulate the myocardial fibrosis caused by the systolic overload of AS. ${ }^{9}{ }^{10}$ Hence, ACE inhibitors may induce more favourable ventricular remodelling.

Regardless of all these potential benefits, AS is considered a classic contraindication to prescribing ACE inhibitors, as is recognised in some textbooks ${ }^{11}{ }^{12}$ and in manufacturers' prescribing information (for Vasotec, Lotensin, Zestril, Altace, and Monopril: www.pdr.net/pdrnet/librarian; and for Capoten: www.rxlist.com). Very recent evidence suggests that ACE inhibitors can be used safely in $\mathrm{AS}^{13}$ and may even be beneficial for patients with symptomatic disease. ${ }^{14}{ }^{15} \mathrm{We}$ designed a drug withdrawal, single blinded, transversal, prospective enrolment study to assess the haemodynamic effects of ACE inhibitors in hypertensive patients with AS. Cardiovascular haemodynamic effects were analysed noninvasively by exercise Doppler echocardiography.

\section{METHODS}

\section{Study population}

The study was approved by the institutional ethics committee and written informed consent was obtained from all patients. Eligible participants were screened among all patients referred to our laboratory with AS diagnosed on echocardiographic examination. Inclusion criteria for the study were moderate or severe AS (peak aortic velocity $\geqslant 2.5 \mathrm{~m} / \mathrm{s}$ and

Abbreviations: $A C E$, angiotensin converting enzyme; $A S$, aortic valve stenosis; LV, left ventricular; MET, metabolic equivalent 
aortic valve area $\leqslant 1.2 \mathrm{~cm}^{2}$ ) and concomitant treatment with an ACE inhibitor for at least three months, prescribed for arterial hypertension. Exclusion criteria were the presence of symptoms related to AS, existence of any other valvar stenosis or regurgitation other than mild $(1+)$, previous cardiac surgery, and absence of a suitable ultrasonic window. After consecutive review of the medical records and telephone interviews with all potential candidates, 27 eligible patients were identified. Five patients did not provide written informed consent. Although 22 patients were randomly assigned to the treatment regimens, one patient did not finish the study. His ejection fraction was normal and mean transvalvar pressure gradient was $70 \mathrm{~mm} \mathrm{Hg}$. After withdrawal of $10 \mathrm{mg}$ /day of enalapril, although he denied any AS symptoms, the exercise test (Bruce protocol) was prematurely interrupted at the fourth minute because of dyspnoea. The blood pressure response was normal. Although he was informed by the investigators of the need for close follow up, he decided to abandon the study. Another patient had pneumonia and her physician discontinued the ACE inhibitor. Therefore, 20 patients completed the study protocol $\left(\right.$ table $\left.1^{16}\right)$.

\section{Study design and clinical data}

Each patient underwent two sets of tests (with and without taking the drug) each of which included a full clinical evaluation, Doppler echocardiogram, and symptom limited stress echocardiography. To minimise the potential confusion effects of exercise training and of the "white coat" phenomenon, participants were randomly allocated to the order in which each set of tests was performed (ACE inhibitors/no ACE inhibitors). The investigators who performed and measured the Doppler echocardiographic and exercise examinations were blinded to this order. ACE inhibitor drug withdrawal and reintroduction were progressive, with a daily dose reduction or increase equivalent to $1.25 \mathrm{mg}$ of enalapril. Once the drug withdrawal or reintroduction scheme was completed, the second study was delayed for a period equivalent to five half lives of each drug. Patients who were not taking ACE inhibitors in the first phase received the first dose two hours after the first set of examinations was completed. Blood pressure was measured daily during the three days before each set of tests. Subjective functional class was assessed by the specific activity scale questionnaire. ${ }^{17}$ Approximate dose equivalents were calculated based on enalapril as the reference, as indicated for the treatment of hypertension. ${ }^{16}$

\section{Doppler echocardiography}

Doppler echocardiograms were recorded digitally with a phased array ultrasound scanner (Acuson Sequoia 256, Siemens, Erlangen, Germany). Ultrasound images and Doppler spectrograms were obtained from standard parasternal, apical, subcostal, and suprasternal views. LV volumes and ejection fraction were measured from biplane four and two chamber apical views. ${ }^{18}$

The methods used to measure stroke volume, cardiac output, mean transvalvar pressure gradient, and aortic valve area, as well as their reproducibility values, have been previously reported for our institution. ${ }^{19}$ Systemic vascular resistance was derived from Doppler derived cardiac output. LV end systolic wall stress (ESS) was calculated as follows ${ }^{20}$ :

$$
\mathrm{ESS}=\frac{\mathrm{LVP}_{\mathrm{s}} \cdot \mathrm{r}_{\mathrm{s}}}{2 \mathrm{~h}_{\mathrm{s}}\left(1+\frac{\mathrm{h}_{\mathrm{s}}}{2 \mathrm{r}_{\mathrm{s}}}\right)}
$$

where $\mathrm{LVP}_{\mathrm{s}}$ is peak LV pressure (systolic blood pressure + peak transvalvar instantaneous pressure gradient), $r_{s}$ is the radius of the LV cavity in systole, and $h_{s}$ is LV posterior wall thickness at end systole. Stroke work loss (SWL) was calculated as follows ${ }^{21}$ :

$$
\text { SWL }=100 \frac{\text { MeanG }}{\text { MeanG }+ \text { SBP }}
$$

where MeanG is the mean pressure gradient and SBP is systolic blood pressure. All measurements were averaged from four to six beats for patients in sinus or pacemaker rhythms and from six to 10 beats for patients in atrial

\begin{tabular}{|c|c|c|c|c|c|c|c|c|c|c|}
\hline Patient & $\begin{array}{l}\text { Age } \\
\text { (years) }\end{array}$ & Sex & SAS & CAD & Rhythm & $\begin{array}{l}\text { LVEF } \\
(\%)\end{array}$ & Drug & $\begin{array}{l}\text { Dose } \\
\text { (mg/day) }\end{array}$ & $\begin{array}{l}\mathrm{DE} \\
\text { (mg/day) }\end{array}$ & $\begin{array}{l}\text { Indexed DE } \\
\left(\mathrm{mg} \cdot \mathrm{m}^{2} / \text { day }\right)\end{array}$ \\
\hline 1 & 68 & Female & $\|$ & No & $\mathrm{AF}$ & 56 & Enalapril & 5 & 5 & 3.2 \\
\hline 2 & 45 & Female & I & No & Sinus & 65 & Enalapril & 5 & 5 & 3.4 \\
\hline 3 & 70 & Male & i & Yes & $\mathrm{AF}$ & 60 & Enalapril & 20 & 20 & 10.8 \\
\hline 4 & 75 & Male & 1 & No & Sinus & 50 & Captopril & 50 & 6.6 & 3.6 \\
\hline 5 & 55 & Male & 1 & No & Sinus & 69 & Captopril & 50 & 6.6 & 3.5 \\
\hline 6 & 74 & Male & I & Yes & $\mathrm{AF}$ & 65 & Captopril & 75 & 10 & 5.5 \\
\hline 7 & 67 & Male & $\|$ & Yes & $\mathrm{AF}$ & 45 & Enalapril & 20 & 20 & 10.6 \\
\hline 8 & 73 & Male & $\|$ & Yes & $\mathrm{AF}$ & 60 & Lisinopril & 20 & 20 & 10.5 \\
\hline 9 & 73 & Female & $\|$ & No & Sinus & 45 & Lisinopril & 5 & 5 & 2.7 \\
\hline 10 & 65 & Female & III & No & Sinus & 67 & Enalapril & 20 & 20 & 11.9 \\
\hline 11 & 80 & Male & 1 & No & Sinus & 63 & Perindopril & 4 & 10 & 5.2 \\
\hline 12 & 83 & Male & 1 & No & Sinus & 63 & Cilazapril & 10 & 30 & 16.0 \\
\hline 13 & 82 & Male & ॥ & Yes & Sinus & 70 & Lisinopril & 20 & 20 & 10.3 \\
\hline 14 & 84 & Female & $\|$ & No & Pacemaker & 65 & Lisinopril & 5 & 5 & 2.7 \\
\hline 15 & 78 & Male & $\|$ & No & $\mathrm{AF}$ & 45 & Captopril & 37.5 & 5 & 2.5 \\
\hline 16 & 68 & Male & 1 & No & Sinus & 66 & Captopril & 25 & 3.3 & 1.6 \\
\hline 17 & 72 & Male & 1 & No & Sinus & 70 & Captopril & 100 & 13.3 & 7.2 \\
\hline 18 & 74 & Male & i & No & Sinus & 70 & Spirapril & 6 & 10 & 5.8 \\
\hline 19 & 72 & Female & $\|$ & No & Sinus & 65 & Enalapril & 40 & 40 & 21.0 \\
\hline 20 & 73 & Female & $\|$ & No & Sinus & 65 & Enalapril & 20 & 20 & 11.6 \\
\hline Median & 73 & & & & & 65 & & & 10 & 5.6 \\
\hline IQR & 8 & & & & & 7 & & & 15 & 7.3 \\
\hline
\end{tabular}
fibrillation. 


\section{Exercise stress echocardiography}

A Bruce or a Naughton (two patients with impaired exercise tolerance) treadmill protocol was used for all except three patients who were unable to perform the test because of functional impairment. Blood pressure was measured noninvasively every minute, as recommended. ${ }^{22-24}$ Prespecified criteria for interrupting the exercise test were appearance of symptoms, fall in or inadequate $(<10 \mathrm{~mm} \mathrm{Hg})$ progression of systolic blood pressure, hypertensive response, frequent ventricular extrasystoles, ventricular tachycardia, bradycardia, new left bundle branch block, or ST segment depression $\geqslant 1.5 \mathrm{~mm}$.

\section{Statistical analysis}

A sample size of 16 was calculated to detect a one metabolic equivalent (MET) difference between exercise tests performed with and without ACE inhibitors in a repeated measures design, assuming a standard deviation of one MET and $\alpha$ and $\beta$ errors of 0.05 and 0.20 , respectively.

Individual data are reported with a single identification label in all tables and figures, allowing tracking of each patient's response across the whole report. Odd number labels identify patients studied with and then without ACE inhibitors. Even number labels identify patients studied in the reverse order. Because most variables are not normally distributed, they are described as median (interquartile range) and compared by exact Wilcoxon paired signed rank tests (S-Plus version 2000, Insightful Inc, Seattle, Washington, USA). Significance was assumed at $\mathrm{p}<0.05$.

\section{RESULTS}

Table 1 summarises baseline clinical and echocardiographic data. The study group consisted mostly of elderly patients with severe asymptomatic disease. Although some patients' specific activity scale was $>$ I, their functional impairment was not attributed to AS either by the referring physician or by the investigators.

\section{Changes related to ACE inhibitor withdrawal}

Drug withdrawal and reintroduction were well tolerated by all patients, and no patient's specific activity scale score was modified during the drug intervention period. Table 2 and fig l show changes in baseline haemodynamic parameters related to drug withdrawal. While taking ACE inhibitors, patients had a lower systolic blood pressure, whereas their diastolic blood pressure did not change. A higher transvalvar pressure gradient while taking ACE inhibitors was observed, whereas aortic valve area was unmodified (fig 1). As a consequence of the reciprocal changes in blood pressure and pressure gradient, LV percentage stroke work loss was higher while patients were taking ACE inhibitors (19 (6)\% $v 14$ $(10) \%$, respectively, $p=0.009)$.

\section{Stress induced haemodynamic changes}

Withdrawal of ACE inhibitors induced no changes either in exercise duration $(7.0$ (2.3) minutes $v 7.0$ (4.1) minutes, $\mathrm{p}=0.4$ ) or in final energy expenditure (fig 2). Although systolic blood pressure and pressure gradient at peak exercise were not modified by the drug intervention, patients had a higher stroke volume during stress while taking ACE inhibitors (fig 2). Also, a trend towards lower diastolic blood pressure at peak stress was observed while patients were not taking ACE inhibitors. The amount of the exercise induced rise in systolic blood pressure and of the decrease in systemic vascular resistance was unmodified by the drug intervention, whereas a trend towards greater increase in stroke volume was observed while patients were taking ACE inhibitors $(\mathrm{p}=0.1)$ (fig 3). The modification induced by ACE withdrawal in stroke volume was closely related to its effect on systemic vascular resistance, both at baseline and during exercise (fig 4).

\section{Abnormal exercise blood pressure responses}

An abnormal exercise induced blood pressure response (fall or failure to rise) was observed in five stress tests from five patients (fig 3A). Two patients had an abnormal blood pressure response while taking ACE inhibitors, which was not reproduced when the drug was discontinued (numbers 15 and 16, fig 3). Excessive vasodilatation was the cause of one of these abnormal responses (number 15, fig 3C), whereas a fall in stroke volume was the cause of the other one (number 16, fig 3B). Remarkably, three patients had an abnormal response while not taking ACE inhibitors that was not observed while they were taking the drug (numbers 1,5 , and 18, fig 3A). The mechanisms were a severe fall in vascular resistance in one patient (number l, fig 3C) and a combined failure to increase stroke volume and decrease in resistance in the other two (numbers 5 and 18, figure 3B, C).

\section{DISCUSSION}

\section{ACE inhibitors in AS}

ACE inhibitors have been classically contraindicated in the presence of AS. In patients with a fixed outflow obstruction, a reduction in systemic vascular resistance is not followed by a proportional increase in cardiac output. Therefore, it is believed that excessive vasodilatation may cause a dangerous fall in coronary or brain perfusion pressure, leading to exercise related symptoms of angina, syncope, or even sudden death. This hypothesis is indirectly based on evidence of a limited coronary flow reserve in patients with AS. ${ }^{25}$

Table 2 Haemodynamic data during and after withdrawal of treatment with angiotensin converting enzyme (ACE) inhibitor

\begin{tabular}{lllll}
\hline & $\begin{array}{l}\text { Treatment } \\
\text { with ACE }\end{array}$ & $\begin{array}{l}\text { After ACE } \\
\text { withdrawal }\end{array}$ & p Value* & $\begin{array}{l}\text { Minimum sample } \\
\text { size for significancet }\end{array}$ \\
\hline Heart rate (beats/min) & $68(29)$ & $70(31)$ & 0.2 & 107 \\
Systolic blood pressure $(\mathrm{mm} \mathrm{Hg})$ & $140(18)$ & $159(12)$ & 0.02 & 71 \\
Diastolic blood pressure $(\mathrm{mm} \mathrm{Hg})$ & $80(10)$ & $80(10)$ & 0.5 & Infinite \\
Stroke volume $(\mathrm{ml})$ & $56(19)$ & $57(35)$ & 0.5 & 356 \\
Cardiac output $(\mathrm{l} / \mathrm{min})$ & $3.7(2.6)$ & $4.0(1.6)$ & 0.4 & 860 \\
Systemic vascular resistance $\left(\mathrm{dyn} \cdot \mathrm{s} \cdot \mathrm{cm}^{-5}\right)$ & $2.290(1.059)$ & $2.153(1.251)$ & 0.8 & 19016 \\
Mean pressure gradient $(\mathrm{mm} \mathrm{Hg})$ & $34(15)$ & $28(18)$ & 0.037 & 16 \\
Aortic valve area $\left(\mathrm{cm}^{2}\right)$ & $0.66(0.39)$ & $0.69(0.34)$ & 0.7 & 2676 \\
LV end systolic wall stress $\left(\mathrm{kdyn} / \mathrm{cm}^{2}\right)$ & $14.0(8.7)$ & $13.5(8.6)$ & 0.3 & 190 \\
\hline
\end{tabular}

Data presented as mean (IQR).

*Exact Wilcoxon paired signed rank test; †calculated with parametric significance tests assuming normally distributed data (significance can be reached with a smaller sample when non-parametric exact tests are used). LV, left ventricular. 

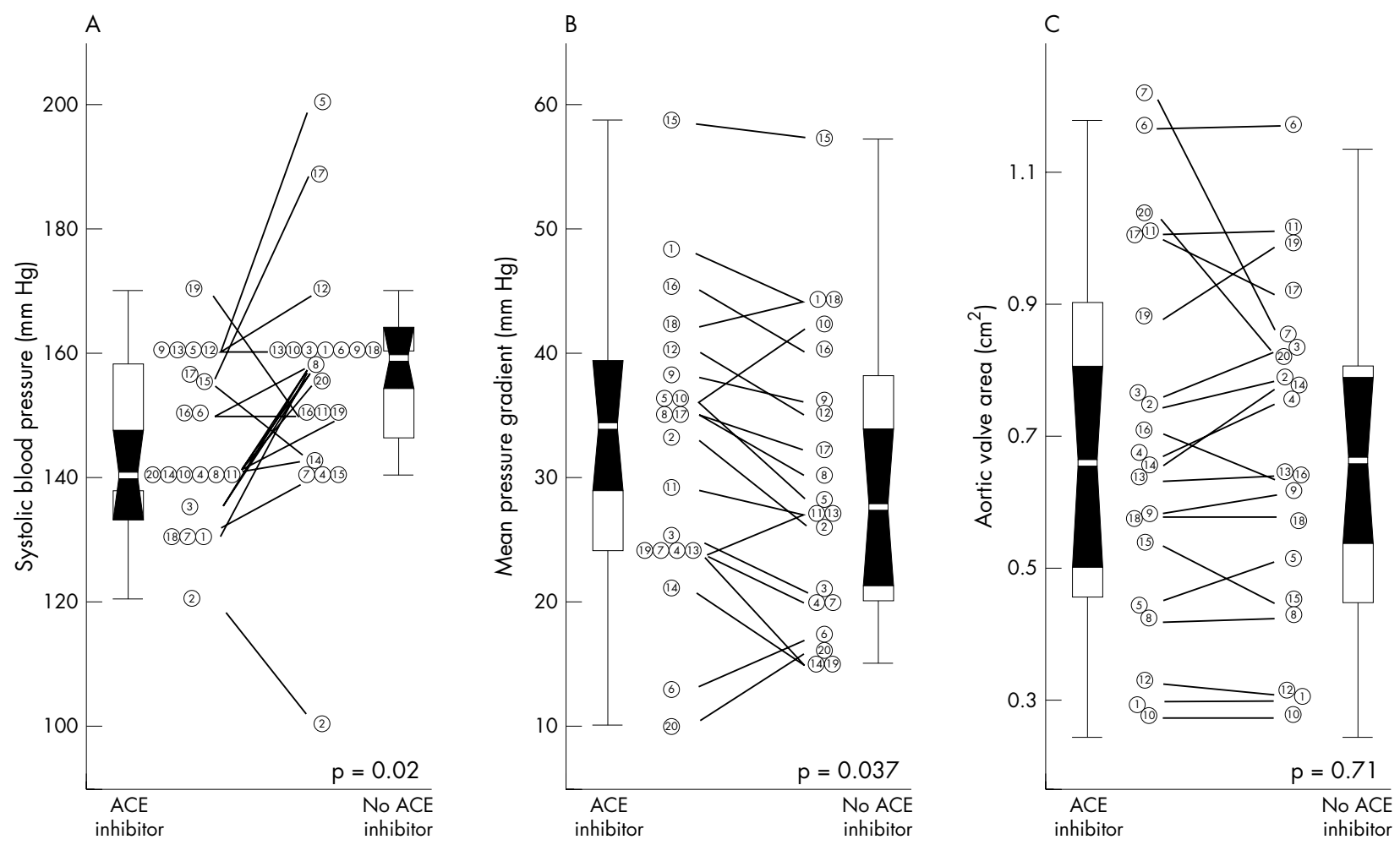

Figure 1 Baseline haemodynamic data. Distributions are shown for (A) systolic blood pressure, (B) mean transvalvar pressure gradient, and (C) aortic valve area. In each panel, the left column shows values for patients while taking angiotensin converting enzyme (ACE) inhibitors and the right column shows values during drug withdrawal. Individual data are presented by a single identifier. Odd numbers identify patients randomly selected to be studied first while taking the drug and even numbers identify patients studied first without taking ACE inhibitors. Each box represents the interquartile distance and the white line represents the median. The shaded zone represents the $95 \%$ confidence interval for the median and the whiskers represent the limits of each distribution.

However, it is not unusual in everyday practice for hypertensive patients with severe AS to be taking ACE inhibitors for a long time with no symptoms or events. On this basis, we designed this pilot study to quantify the functional and haemodynamic effects related to ACE inhibitor drug withdrawal in this particular population.

Only a few studies have previously assessed the effects of ACE inhibitors in AS. Martínez Sanchez et $a l^{26}$ analysed the acute haemodynamic effects of captopril administration in 22 patients with severe AS. By using right heart catheterisation, these authors observed beneficial haemodynamic effects such as a decrease in systemic vascular resistance and an increase in cardiac output; unfortunately, neither valvar nor coronary haemodynamic effects were specifically analysed in their study. Recently, a pilot blinded, randomised, placebo controlled study assessed the haemodynamic and functional effects of enalapril in symptomatic patients with severe AS. ${ }^{15}$ In patients with normal LV systolic function, the drug was well tolerated and significantly improved functional class during follow up. Also, the short term effects of ramipril have been shown to be well tolerated by asymptomatic patients with mild to moderate AS undergoing an open label titration study. ${ }^{13}$

Regardless of the small sample size, we were able to characterise some important haemodynamic benefits of ACE inhibitors in hypertensive patients with AS. While taking the drug, AS patients achieved a higher stroke volume during exercise. As expected, rest systolic blood pressure was lower while patients were taking the drug. However, more important, there were no significant differences in diastolic pressure either at baseline or during exercise. In fact, a nearly significant trend towards higher diastolic pressure during exercise was observed while patients were taking the drug. These findings, associated with the behaviour of stroke volume at peak stress, suggest a potentially beneficial effect of ACE inhibitors on exercise haemodynamic function in hypertensive patients with AS. Our study shows that the hypothesis of a hazardous effect of these drugs on exercise mediated hypoperfusion seems unlikely in hypertensive patients with AS. Further randomised, large scale placebo controlled studies should reassess these findings before the use of ACE inhibitors can become widespread. ${ }^{27}$

Some other potential beneficial effects justify a controlled trial on the role of ACE inhibition in patients with AS. Intracoronary administration of enalapril has been shown to improve diastolic function acutely in patients with AS. ${ }^{28}$ Also, experimental data indicate that activation of the reninangiotensin-aldosterone system contributes to cardiac fibrosis in animals and patients with AS and may be associated with unfavourable haemodynamic effects. ${ }^{9}{ }^{10}$ Furthermore, ACE and angiotensin II are also present in the extracellular matrix of degenerative aortic valves with stenotic lesions and may have a role in lesion development and progression. ${ }^{8}$ Consequently, some investigators have questioned the contraindication of ACE inhibitors in AS in situations of concomitant hypertension, asymptomatic status, or heart failure. ${ }^{1429} 30$

\section{Extrinsic and intrinsic load in AS}

Interestingly, we observed a significant decrease in the transvalvar pressure gradient while patients were not taking the ACE inhibitor drug, reciprocal to their increase in blood pressure. Nitroprusside had an identical effect in patients with AS with impaired LV systolic function: as peripheral 

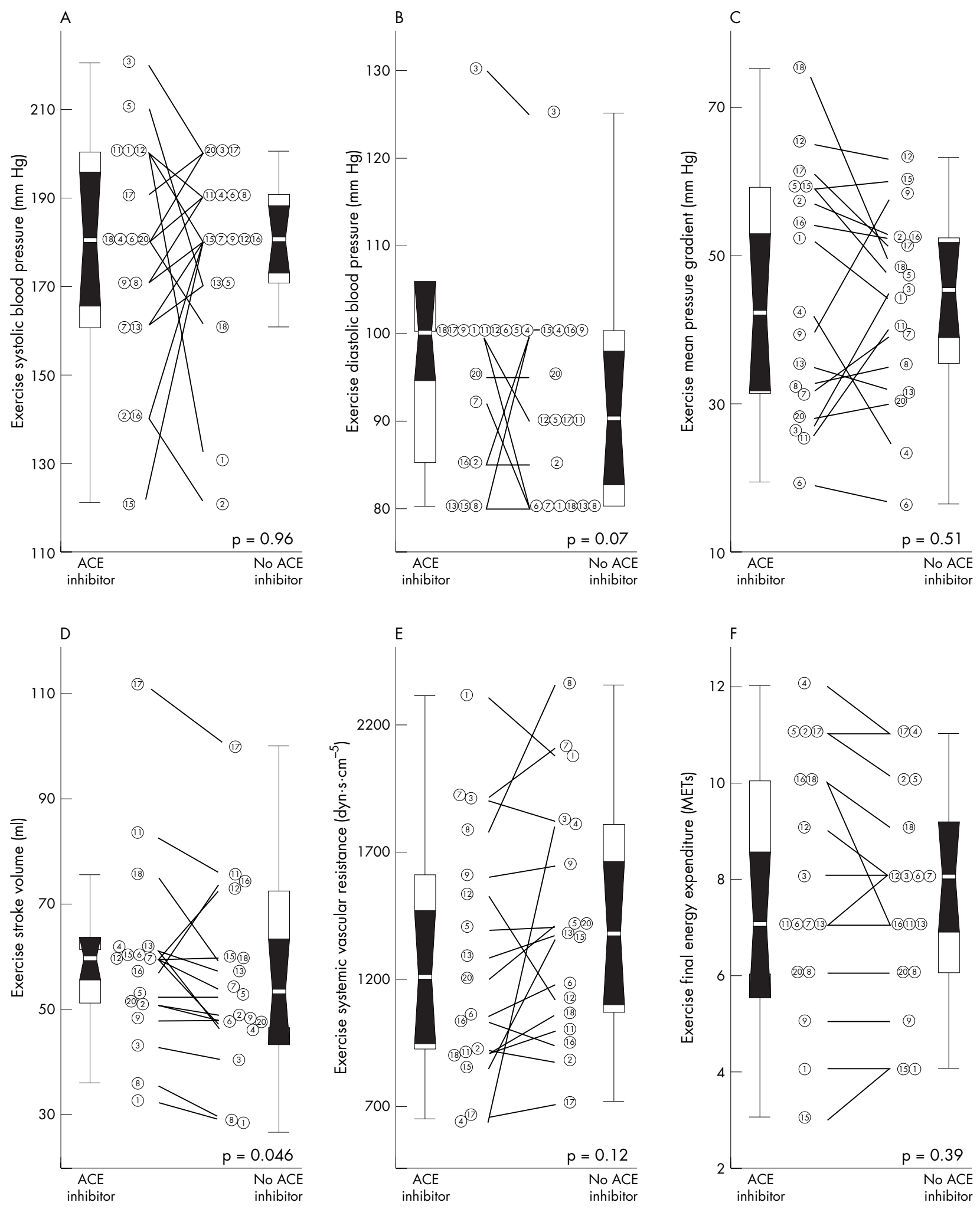

Figure 2 Haemodynamic data during exercise. Distributions are shown for peak exercise (A) systolic and (B) diastolic blood pressure, (C) mean transvalvar pressure gradient, (D) stroke volume, (E) systemic vascular resistance, and (F) final energy expenditure. Data are presented as in fig 1.

resistance decreased, the transvalvar pressure gradient rose. ${ }^{31}$ The present study illustrates how modification of the pressure gradient blunts the response induced by vasodilators in systolic LV pressure and, consequently, in global end systolic stress.
Reciprocal changes in the transvalvar pressure gradient and blood pressure are the consequence of the well characterised complementary and competitive interaction between intrinsic and extrinsic systolic load observed in situations of LV outflow obstruction. ${ }^{32}$ As shown in a recent 

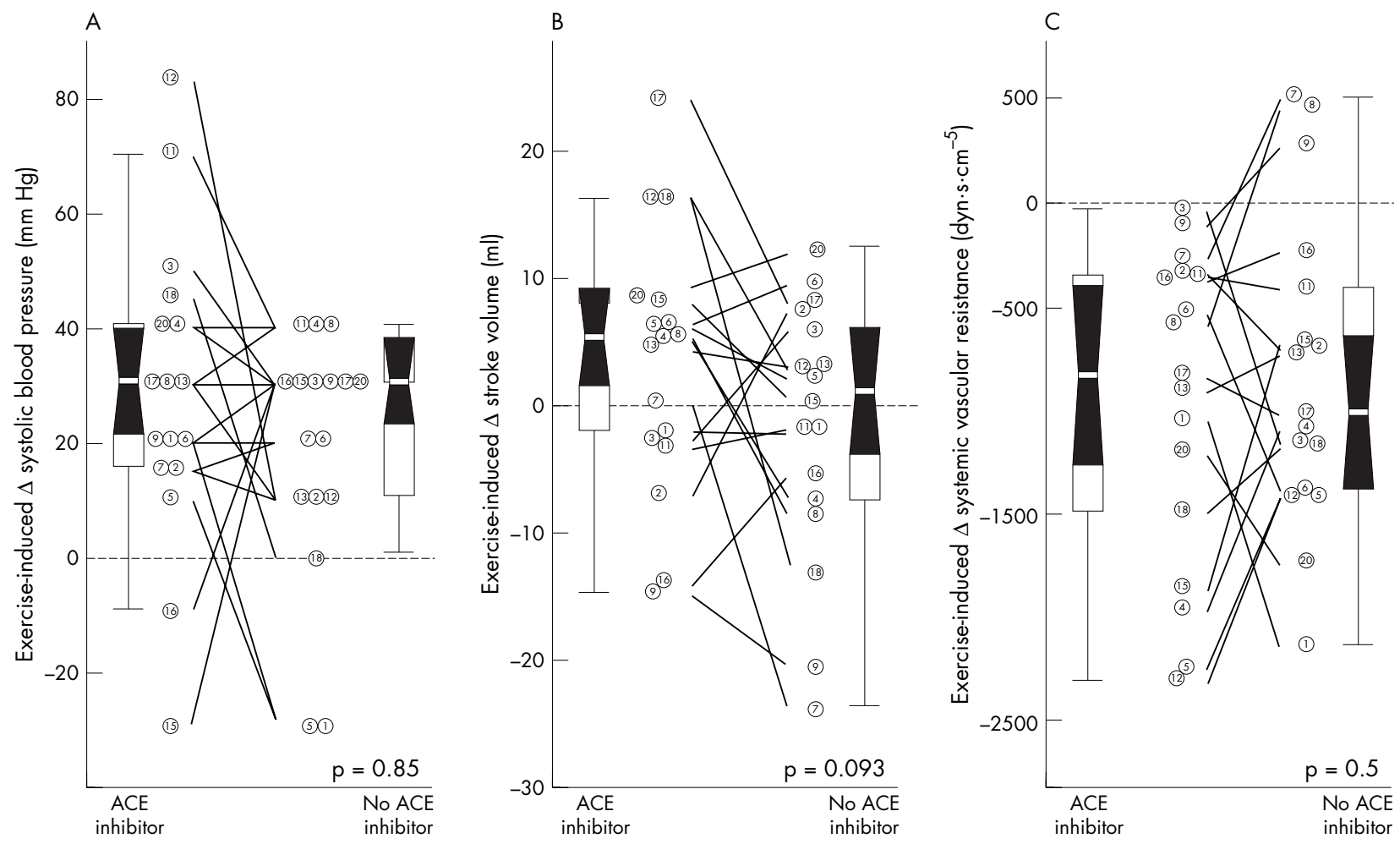

Figure 3 Haemodynamic changes induced by exercise. Exercise induced changes ( $\Delta$ ) in (A) systolic blood pressure, (B) stroke volume, and (C) systemic vascular resistance are shown. Data are presented as in fig 1.

animal study, an intervention on aortic pressure alters transvalvar flow rate and, if valve area remains constant, modifies the transvalvar gradient in parallel. ${ }^{33}$ Further studies are required to clarify the basis of the vascular-valvarventricular coupling, since other mechanisms of interaction have been proposed. ${ }^{21} 27$ 33-35

The present study shows that patients with significant AS do not have a truly fixed stroke volume. Instead, modifying the vasodilator treatment had a direct effect on stroke volume, as fig 4 shows. The increase in peripheral resistance induced by drug withdrawal was followed by a reciprocal decrease of stroke volume, even in patients with critical AS and normal LV systolic function. This finding is in agreement with the hypothesis of the double loaded LV, according to which the extrinsic systolic load remains as a major determinant of ventricular performance, even in the presence of a severe outflow obstruction. Consequently, we believe this evidence supports the use of ACE inhibitors by patients presenting with symptoms of congestive heart failure or with critical AS and who do not undergo valve replacement for whatever reason. ${ }^{14}{ }^{15}$ Nevertheless, ACE inhibitors should be introduced with caution to avoid symptomatic hypotension, particularly in the presence of LV systolic dysfunction. ${ }^{15}$

\section{Implications for assessing disease progression}

The effect of vasodilators on non-flow corrected indices of severity such as transvalvar velocity, pressure gradient, or LV stroke work loss obviously needs to be taken into account if a placebo controlled study is designed to assess the impact of ACE inhibitors on disease progression. It is noteworthy that a number of longitudinal studies have shown these non-flow corrected indices to be the best predictors of outcome in patients with AS. ${ }^{21} 3637$ In asymptomatic patients, higher values of pressure gradient, aortic jet velocity, and stroke work loss are known to be associated with earlier development of symptoms, need for valve replacement, and cardiovascular death. Furthermore, for a similar degree of valvar obstruction, a higher stroke volume has been shown to correlate directly with more rapidly progressing AS. ${ }^{38}$ Our study shows that ACE inhibitors, by augmenting flow rate, modify all non-flow corrected indices of severity. Consequently, we believe that these potentially harmful haemodynamic effects of vasodilators in AS should be considered for the selection of the specific ACE inhibitor drug and dose to be tested in future clinical trials.

\section{The role of exercise testing in AS}

The role of exercise testing has been increasing in importance in guiding management of patients with AS. Hypotension or a failure to increase blood pressure during exercise correlates with a poor outcome in patients with $\mathrm{AS}^{39}$ and is accepted as a class II-A recommendation for valve surgery by some investigators $^{24}$ and scientific committees. ${ }^{40}$ However, the reproducibility and the effect of vasodilator drugs on the haemodynamic response to exercise had never been assessed in AS. It is remarkable that all the patients in our study who had an abnormal blood pressure response during exercise also had a normal response either in the previous or in the following test. The abnormal blood pressure response was observed in three patients in their first study and in two patients in their second. We believe that the lack of reproducibility of the abnormal blood pressure response is most probably related to the drug intervention, since the confusing effect related to training was controlled by randomisation. The findings of our study suggest that the results of exercise testing need to be interpreted taking into account patients' medication. If surgery in an asymptomatic patient is being considered on the basis of an abnormal haemodynamic response during an exercise test, the examination may require reassessment after the drug prescription is modified. 

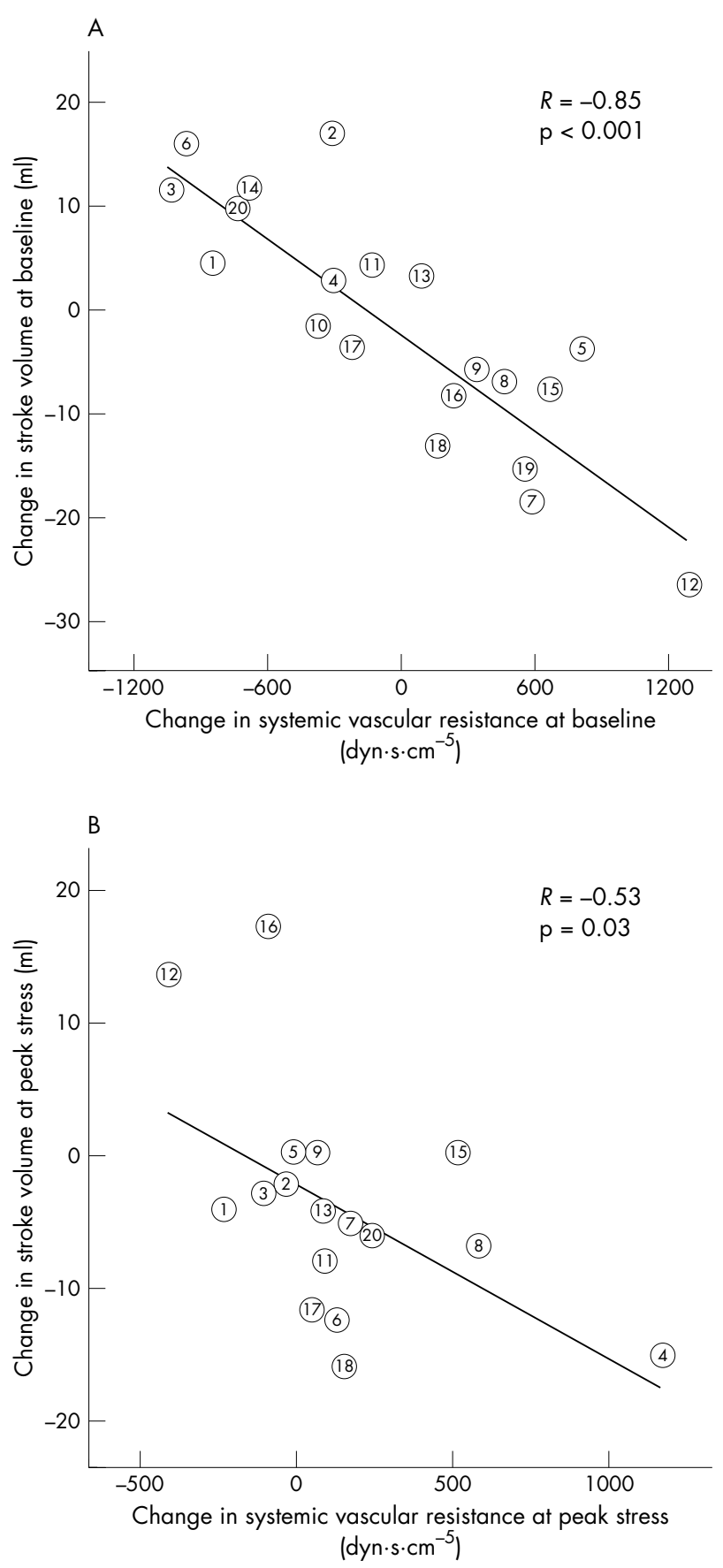

Figure 4 Impact on stroke volume of the modification of systemic vascular resistance induced by drug withdrawal. The change in systemic vascular resistance induced by the drug intervention (before minus after withdrawal) is shown in the horizontal axis and the modification in stroke volume is shown in the vertical axis. (A) Data at baseline; (B) data at peak exercise.

\section{Study limitations}

The most obvious limitation of the study is sample size, since it would have been possible to observe further significant differences in a larger study sample. Owing to the study design, it was unlikely that we would have detected any serious adverse events in our study. The study was dimensioned to detect a clinically significant change in functional capacity (one MET) in either direction, related to the administration or discontinuation of the drug. Table 2 lists the minimum sample size of patients who would have needed to be enrolled to find significant differences in baseline haemodynamic variables. Following a pathophysiological pilot design, the purpose of the study is obviously far from that of a prospective drug intervention placebo controlled study. The fact that all patients were already taking the drugs for long periods before enrolment obviously causes a selection bias regarding tolerability. However, we believe our results may help to clarify the expected acute benefits and risks related to the use of ACE inhibitors in hypertensive patients with AS. For this purpose, we believe the sample size data that we provided may be helpful.

Differences in the specific compound and doses of ACE inhibitor drugs may have been responsible for the scattered effects observed in the study. Although we attempted to analyse an overall haemodynamic class effect for ACE inhibitors, the particular agents may not all behave identically.

\section{Conclusions}

Hypertensive patients with AS should not discontinue ACE inhibitors. In AS, the afterload reduction caused by ACE inhibitors is partially blunted by a parallel increase in the transvalvar pressure gradient. However, ACE inhibitors favourably affect stress haemodynamic variables in most hypertensive patients with AS. Prospective randomised studies to define the role of ACE inhibitors in AS are warranted.

\section{ACKNOWLEDGMENTS}

We thank all the personnel of the Echocardiography and Exercise Test Laboratories for their collaboration throughout the study.

\section{Authors' affiliations}

J Jiménez-Candil*, J Bermejo, R Yotti, C Cortina, M Moreno, J L Cantalapiedra, M A García-Fernández, Department of Cardiology, Hospital General Universitario Gregorio Marañón, Madrid, Spain

${ }^{*}$ Current address: Department of Cardiology, Hospital Clínico, Salamanca, Spain

Potential conflicts of interest: None to disclose.

\section{REFERENCES}

1 Stewart BF, Siscovick D, Lind BK, et al. Clinical factors associated with calcific aortic valve disease. Cardiovascular health study. J Am Coll Cardiol 1997:29:630-4.

2 Antonini-Canterin F, Huang G, Cervesato E, et al. Symptomatic aortic stenosis: does systemic hypertension play an additional role? Hypertension 2003;41:1268-72.

3 Otto CM, Lind BK, Kitzman DW, et al. Association of aortic-valve sclerosis with cardiovascular mortality and morbidity in the elderly. N Engl J Med 1999;341:142-7.

4 Braunwald E. Valvular heart disease. In: Braunwald E, ed. Heart disease: a textbook of cardiovascular medicine, 5th edn. Philadelphia: Saunders, 1997:1007-76.

5 Yusuf S, Pepine CJ, Garces C, et al. Effect of enalapril on myocardial infarction and unstable angina in patients with low ejection fractions. Lancet 1992;340: $1173-8$.

6 Lewis EJ, Hunsicker LG, Bain RP, et al. The effect of angiotensin-convertingenzyme inhibition on diabetic nephropathy. The Collaborative Study Group. N Engl J Med 1993;329:1456-62.

7 Yusuf S, Sleight P, Pogue J, et al. Effects of an angiotensin-converting-enzyme inhibitor, ramipril, on cardiovascular events in high-risk patients. The Heart Outcomes Prevention Evaluation Study Investigators. N Engl J Med 2000:342: 145-53

8 O'Brien KD, Shavelle DM, Caulfield MT, et al. Association of angiotensinconverting enzyme with low-density lipoprotein in aortic valvular lesions and in human plasma. Circulation 2002; 106:2224-30.

9 Weinberg EO, Schoen FJ, George D, et al. Angiotensin-converting enzyme inhibition prolongs survival and modifies the transition to heart failure in rats with pressure overload hypertrophy due to ascending aortic stenosis. Circulation 1994;90:1410-22.

10 Fielitz J, Hein S, Mitrovic V, et al. Activation of the cardiac renin-angiotensin system and increased myocardial collagen expression in human aortic valve disease. J Am Coll Cardiol 2001;37:1443-9.

11 Opie LH. ACE inhibitors. In: Opie LH, ed. Drugs of the heart. 4th edn. Philadelphia: Saunders, 1995:132. 
12 Carabello BA, Stewart WJ, Crawford FA. Aortic valve disease. In: Topol E, ed. Textbook of cardiovascular medicine. Philadelphia: Lippincott-Raven, 1998:533-55.

13 O'Brien KD, Zhao XQ, Shavelle DM, et al. Hemodynamic effects of the angiotensin-converting enzyme inhibitor, ramipril, in patients with mild to moderate aortic stenosis and preserved left ventricular function. J Investig Med 2004;52:185-91.

14 Ahmed A, Kiefe Cl, Allman RM, et al. Survival benefits of angiotensinconverting enzyme inhibitors in older heart failure patients with perceived contraindications. J Am Geriatr Soc 2002:50:1659-66.

15 Chockalingam A, Venkatesan S, Subramaniam T, et al. Safety and efficacy of angiotensin-converting enzyme inhibitors in symptomatic severe aortic stenosis: Symptomatic cardiac obstruction-pilot study of enalapril in aortic stenosis (SCOPE-AS). Am Heart J 2004;147:E19.

16 Hutchinson TA, Shahan TR. DRUGDEX ${ }^{\circledR}$ system. Greenwood Village: MICROMEDEX, 2002

17 Goldman L, Hashimoto B, Cook EF, et al. Comparative reproducibility and validity of systems for assessing cardiovascular functional class: advantages of a new specific activity scale. Circulation 1981;64:1227-34.

18 American Society of Echocardiography Committee on Standards. Recommendations for quantification of the left ventricle by two-dimensional echocardiography. J Am Soc Echocardiogr 1989;2:358-67.

19 Bermejo J, Garcia-Fernandez MA, Torrecilla EG, et al. Effects of dobutamine on Doppler echocardiographic indexes of aortic stenosis. J Am Coll Cardiol 1996;28:1206-13.

20 Reichek N, Wilson J, St John Sutton M, et al. Noninvasive determination of left ventricular end-systolic stress: validation of the method and initial application. Circulation 1982;65:99-108.

21 Bermejo J, Odreman R, Feijoo J, et al. Clinical efficacy of Dopplerechocardiographic indices of aortic valve stenosis: a comparative test-based analysis of outcome. J Am Coll Cardiol 2003;41:142-51.

22 Atwood JE, Kawanishi S, Myers J, et al. Exercise testing in patients with aortic stenosis. Chest 1988;93:1083-7.

23 Munt $\mathrm{BI}$, Otto CM. Utility of stress testing in valvular aortic stenosis. Cardiol Rev 1997; 5:55-62

24 Chambers J. Exercise testing to guide surgery in aortic stenosis [editorial]. Heart 1999;82:7-8

25 Marcus ML, Doty DB, Hiratzka LF, et al. Decreased coronary reserve: a mechanism for angina pectoris in patients with aortic stenosis and normal coronary arteries. N Engl J Med 1982;307:1362-6.
26 Martinez Sanchez C, Henne O Arceo A et al. Efectos hemodinámicso del captopril oral en pacientes con estenosis aórtica crítica. Arch Inst Cardiol Mex 1996;66:322-30.

27 Bermejo J, Rojo-Alvarez JL, Antoranz JC, et al. Estimation of the end of ejection in aortic stenosis: an unreported source of error in the invasive assessment of severity. Circulation 2004;110:1114-20.

28 Friedrich SP, Lorell BH, Rousseau MF, et al. Intracardiac angiotensinconverting enzyme inhibition improves diastolic function in patients with left ventricular hypertrophy due to aortic stenosis. Circulation 1994:90:2761-71.

29 Cox NL, Abdul-Hamid AR, Mulley GP. Why deny ACE inhibitors to patients with aortic stenosis? Lancet 1998;352:111-2.

30 Routledge HC, Townend JN. ACE inhibition in aortic stenosis: dangerous medicine or golden opportunity? J Hum Hypertens 2001;15:659-67.

31 Khot UN, Novaro GM, Popovic ZB, et al. Nitroprusside in critically ill patients with left ventricular dysfunction and aortic stenosis. N Engl J Med 2003;348:1756-63.

32 Pasipoularides A. Clinical assessment of ventricular ejection dynamics with and without outflow obstruction. J Am Coll Cardiol 1990;15:859-82.

33 Kadem L, Dusmenil JG, Rieu R, et al. Impact of systemic hypertension on the assessment of aortic stenosis. Heart 2005;91:354-61.

34 Bermejo J. The effect of hypertension on aortic valve stenosis. Heart 2005;91:280-2.

35 Laskey WK, Kussmaul WG, Noordergraaf A. Valvular and systemic arterial hemodynamics in aortic valve stenosis: a model-based approach. Circulation 1995:92:1473-8

36 Otto CM, Burwash IG, Legget ME, et al. Prospective study of asymptomatic valvular aortic stenosis: clinical, echocardiographic, and exercise predictors of outcome. Circulation 1997;95:2262-70.

37 Rosenhek R, Binder T, Porenta G, et al. Predictors of outcome in severe, asymptomatic aortic stenosis. N Engl J Med 2000;343:611-7.

38 Palta S, Pai AM, Gill KS, et al. New insights into the progression of aortic stenosis: implications for secondary prevention. Circulation 2000;101:2497-502.

39 Amato MCM, Moffa PJ, Werner KE, et al. Treatment decision in asymptomatic aortic valve stenosis: role of exercise testing. Heart 2001;86:381-6.

40 lung B, Gohlke-Barwolf C, Tornos P, et al. Recommendations on the management of the asymptomatic patient with valvular heart disease. Eur Heart J 2002;23:1252-66

\section{IMAGES IN CARDIOLOGY}

\section{Thebesian venous lake}

A

50 year old woman with end stage renal disease status post renal transplant presented with chest pain and was found to have coronary artery disease on coronary angiography. During performance of a left ventriculogram with a hand injection using a JR4 catheter, serendipitous cannulation and injection of a large thebesian vein occurred with prompt visualisation of cardiac veins and the coronary sinus. There was a large thebesian "venous lake" connection between the endocardial surface of the ventricle and the coronary sinus (panel). Such "venous lake" connections have not been reported before. Thebesian veins can be communications between the capillary bed to the ventricles, direct arterial connection to the ventricles or venoluminal vessels, or direct communication from the coronary vein into the ventricles. Venoluminal thebesian veins are thought to be more common in the atria than in the ventricle, and more common in the right ventricle than the left ventricle.

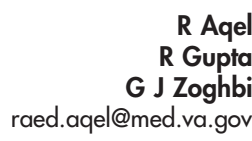

R Aqel J Zoghbi

raed.aqe@@med.va.gov

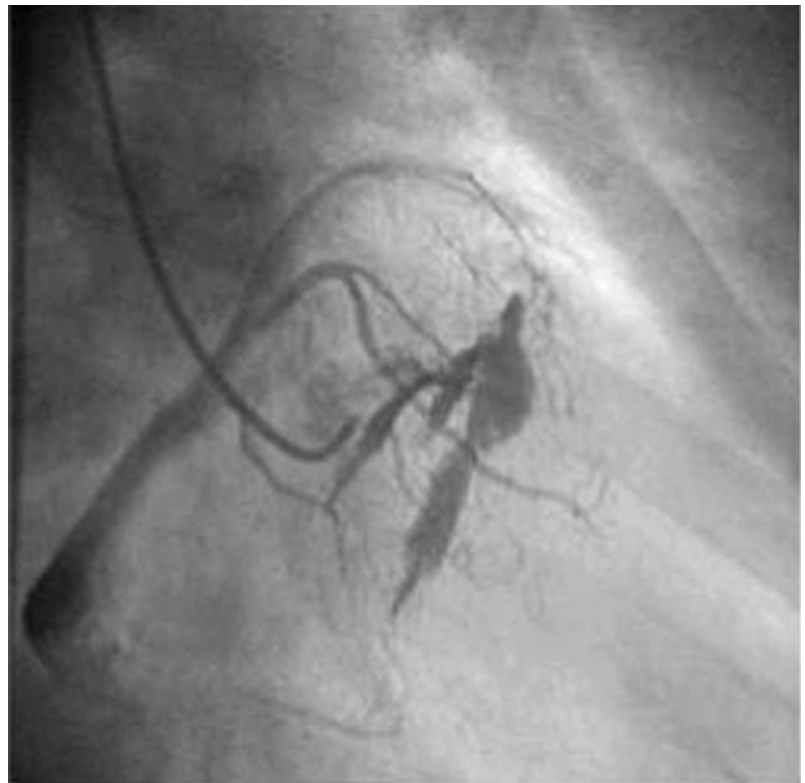

Direct cannulation of the thebesian vein via a JR4 catheter in the left ventricle was serendipitously achieved. This RAO projection shows a large thebesian "venous lake" connecting the ventricular lumen to the cardiac veins and antegrade filling of the coronary sinus is demonstrated. 